\title{
AC 2007-1099: MEASURING THE VALUE OF COURSE COMPONENTS IN THE ONLINE CLASSROOM
}

\section{Alice Squires, Stevens Institute of Technology}

Alice Squires is the Director for Online Programs for the School of Systems and Enterprises, Stevens Institute of Technology in Hoboken, NJ. Alice also teaches systems engineering as a faculty at Stevens and business and management as a faculty at University of Phoenix.

Alice graduated magna cum laude with a Bachelor of Science of Electrical Engineering (BSEE) at University of Maryland in 1984 and Summa cum Laude with Recognition with a Masters of Business Administration (MBA) at George Mason University in 1996. She is concurrently pursuing her doctoral research at Stevens in systems engineering and intelligent / adaptive online learning systems. As the primary author of this paper, please address all related communications to her at: asquires@stevens.edu.

Early in her career Alice focused on engineering hardware design and related software development, followed by technical management and operations management, with a more recent focus on systems engineering and online education and training. She has over twenty years of experience in engineering project management and technical management primarily in the defense sector.

She has worked directly for several large defense companies including General Dynamics, Lockheed Martin and IBM. At General Dynamics, she managed the requirements and integration and testing for the vehicle electronics on the Advanced Amphibious Assault Vehicle (AAAV) built for the United States Marines. Prior to this she managed the production system and cost center for Lockheed Martin's (now BAE Systems') radiation-hardened manufacturing line. At IBM she worked as a technical lead on various defense related contracts. She has also worked for several smaller companies including Delex Systems (Navy and tactical trainers), Agere Systems (telecommunications) and ASSETT, Inc (Navy and signal processing). She received the General Dynamics Technical Achievement in Safety Award in 2002, the Lockheed Martin Outstanding Team Award in 1998, the MBA Fellowship from 1994-1995 and multiple technical and suggestion awards from IBM from 1986 to 1993.

\section{Mike Pennotti, Stevens Institute of Technology}

Michael Pennotti is Industry Professor and Associate Dean for Professional Programs, for the School of Systems and Enterprises, Stevens Institute of Technology.

As a systems engineering leader for more than thirty years, Dr. Pennotti has broad experience with both technical and organizational systems. He spent the first twenty years of his career at Bell Laboratories, designing, analyzing and improving the operational performance of three generations of anti-submarine warfare systems for the United States Navy. From 1984 to 1990 he was Director of Advanced ASW Concepts at Bell Labs.

In 1990, Mike shifted his focus from R\&D to general management, and over the next ten years, served on the senior leadership teams of three different AT\&T and Lucent Technologies businesses. As Quality Director for AT\&T Business Communications Systems, he led the \$3.5B unit to a Baldrige site visit in 1996. As Human Resources Vice President for Lucent's Enterprise Networks Group, he helped develop and execute people strategies that supported a doubling in th e size of that business in three years. As VP Quality for Avaya, he established the initial business processes for this \$8B Lucent spin-off.

Mike also has experience as an independent consultant, applying the principles of process management and performance improvement to the solution of business problems for early stage, high-tech companies. A paper on that work was published in a special issue of the Engineering Management Journal. 
Since joining Stevens in 2001, Mike has taught courses in systems engineering, system architecture and design, requirements engineering and management, systems engineering for thought leadership in systems engineering, and systems thinking. His courses have been enthusiastically received by students from defense and commercial industries and government agencies, both within the U.S. and around the world. He has also developed and delivered highly successful web-based versions of two of his courses.

Dr. Pennotti is a member of the International Council on Systems Engineering, a senior member of both the IEEE and the American Society for Quality. He holds Ph.D. and MS degrees in Electrical Engineering from the Polytechnic Institute of New York, a BEE from Manhattan College, and is a graduate of the AEA/Stanford Executive Institute for the management of high-technology companies. 


\title{
Measuring the Value of Course Components Applied in the Online Classroom
}

\begin{abstract}
This paper compares online course components and related student evaluations for twelve Systems Engineering and Engineering Management (SEEM) courses offered a total of thirty-seven times to 483 students through the online Webcampus system at the Stevens Institute of Technology from Fall 2005 through Fall 2006. The comparative results are used to identify those components of the online classroom that had the greatest positive impact on student satisfaction in two areas: the perceived quality of the course and the perceived effectiveness of the instructor.
\end{abstract}

\section{Introduction}

Online education is still in the discovery stage of development. Translating proven faceto-face or ground courses and their related course material from the live classroom to the online classroom, in a way that preserves the original learning objectives, is a work in progress at most forward thinking universities. International learning cultures have been built around open online courseware offered free by MIT, and Yale University has recently announced its intention to videotape live faculty lectures for seven existing courses and make the videos publicly available starting Fall 2007. While the demand for online education is clearly exploding, most university faculty are just beginning to develop experience in this arena. Educators are in the experimental stage in identifying those components of the online course that produce the greatest value as part of the overall online learning experience.

However, one area that asynchronous learning research consistently emphasizes is the importance of interactions among students and between the instructor and the students. (Frederickson et al, 2000; Garrison et al, 2001; Swan et al, 2000) Swan et al, when researching asynchronous online learning, found: “...three (and only three) course design factors that contribute significantly to the success of online courses. These are a transparent interface, an instructor who interacts frequently and constructively with students, and a valued and dynamic discussion." (Swan et al, 2000, p. 517) Given the asynchronous and remote nature of our university's online courses, our experience has been that student-faculty interaction, student-student interaction, and faculty feedback are among the top components that drive a successful online learning experience. Success in these cases is defined by a high level of student satisfaction with the instructor and the course, as well as a high level of student performance.

This paper focuses on the area of student satisfaction. Student satisfaction is an important metric in the evolution of asynchronous online learning and the legitimization of online versus classroom education. (Sener et al, 2002) Student satisfaction and success in the online environment is linked to both student performance and student learning in the following way: "One of the critical factors for the success of on-line learning is the valuing of student performance by the instructors. This can take many 
forms. A particularly good example is on-line discussion. When on-line discussion is valued (graded), authentic (involves real questions), and frequent, when interactions are positive and enthusiastic, students learn more and are happier." (Frederickson et al, 2000, p.36) Clearly, satisfied students are more open to the learning experience and are therefore better able to perform at the level required to excel in the course.

"Student/teacher and student/student interaction is also critical to successful on-line learning. Frequent, positive, and personal interactions can help bridge the communication gap created when face-to-face courses are moved on-line." (Frederickson et al, 2000, p.36) From this we can conclude that ongoing faculty feedback and a high level of online interactions between both the faculty and the student, and students to students, are basic requirements for creating a successful online learning experience. This paper analyzes these and other components of the online classroom against student-reported satisfaction with course quality and instructor effectiveness. In our paper, thirty-seven instantiations of twelve different Systems Engineering and Engineering Management (SEEM) courses over four semesters from Fall 2005 to Fall 2006, inclusive, are compared with the results of student evaluations of those courses.

To complete this comparison, we first define a baseline architecture for the online classroom as an infrastructure in which to do the comparison. Next, we identify a methodology to measure the degree to which each component of the online classroom was included in each of the online courses being evaluated. We then compile results from the student evaluations and correlate the student feedback on course quality and instructor effectiveness to the various components used in each instantiation of the course. Finally, we present the findings and identify those components that appear to add the most value to the online course learning experience, based on the students' perceptions.

\section{Background}

The Stevens Institute of Technology Webcampus program and the Systems Engineering and Engineering Management (SEEM) department's online educational approach is founded on an 'anywhere, anytime' instructional framework. The courses are fully asynchronous to provide complete flexibility in scheduling; however, important elements of the classroom such as faculty-student and student-student interactions and team projects are preserved. Our department objectives are to provide equivalent in-class learning with comparable student feedback and a manageable instructor course load. We have previously defined a framework for our department's online courses and have shown that we can meet our objectives in an asynchronous online version of our graduate level course Fundamentals of Systems Engineering. (Pennotti et al, 2004)

A typical online course at the Stevens Institute of Technology consists of the delivery of course content by an experienced instructor to remote students over the Internet. Each instructor sets up their course in the university's Web Course Tools (WebCT) Learning Management System (LMS) as part of the Webcampus program. Courses include a student code of conduct, a faculty introduction or profile, a course syllabus and/or an 
overview for getting started, course material including lecture notes and additional resources, chat rooms and discussion groups, and other useful information and links. Each course contains the necessary components to address Moore's (1989) three types of interaction: learner-content, learner-instructor, and learner-learner; as well as Hillman's (1994) fourth type of interaction: learner-interface. Interactions in the online environment “...can be defined as active learning”. (Parker, 1999, p. 14)

The learner-content interaction, the private interaction between the learner and course content, takes place when the student reads and reviews the course material posted in the online classroom and/or sent to the student on a CD. Instructors use various approaches for providing course content. The course material can consist of a course syllabus and/or a getting started overview, posted in-class presentation slides, lecture notes, recorded audio based lectures, assignment descriptions, textbooks, articles, links and additional resources and supplemental material.

The learner-instructor interaction, the dialog and feedback between the learner and instructor, is implemented through many mechanisms. During the online course, the instructor proactively interacts with the students in a variety of ways, depending on the style and preferences of the instructor, as well as the nature of the course content. Instructors use a combination of weekly online discussions, e-mail, web conferencing, and phone calls to communicate with the students. In some courses, the instructor proactively participates in the online course by frequently engaging the students in weekly discussions and promptly answering questions on the course material. The instructor communicates with the students asynchronously through the online discussion groups and classroom mail. Some instructors use their regular e-mail to communicate directly to the students outside of the classroom. The type and level of instructor feedback varies by course and instructor. Instructors typically provide feedback to the student weekly throughout the course in the form of grades and/or cursory to detailed written feedback. Interaction may also be provided via the phone, as needed, and via weekly or intermittent web conferencing.

In many of the courses, the learner-learner interaction, involving the exchange of information and ideas between the learners, is actively implemented in the online course environment through online discussion and/or team project work. During many of the courses, teams go offline to discuss the course content and work on their team projects. And finally, the learner-interface interaction, the interaction between the learner and the technology, is inherent in any online classroom. This interaction includes the course access method, login process and course appearance.

\section{A Baseline Online Classroom Architecture}

As the first step in our analysis, we need to define a baseline architecture that contains the course components used in the online classroom. A previous baseline architecture for the Systems Engineering and Engineering Management (SEEM) department's initial online course, Fundamentals of Systems Engineering, consisted of four key elements (Pennotti et al, 2004): 
1. Getting started instructions that prepare learners for participating in the course.

2. Course content which learners use to understand the course concepts.

3. A team project to apply the course concepts in a controlled but realistic environment.

4. Online discussions to share both learner and instructor experiences and perspectives.

For this paper, we developed a broader architecture that encompasses the variety of course formats and instructor approaches both in the SEEM department and in other departments and colleges within the Stevens Institute of Technology's Webcampus. The interface for these courses is provided through WebCT and Interwise web conferencing applications. At a system level view, the architecture for these online classrooms is divided into three major components, as shown in Figure 1.

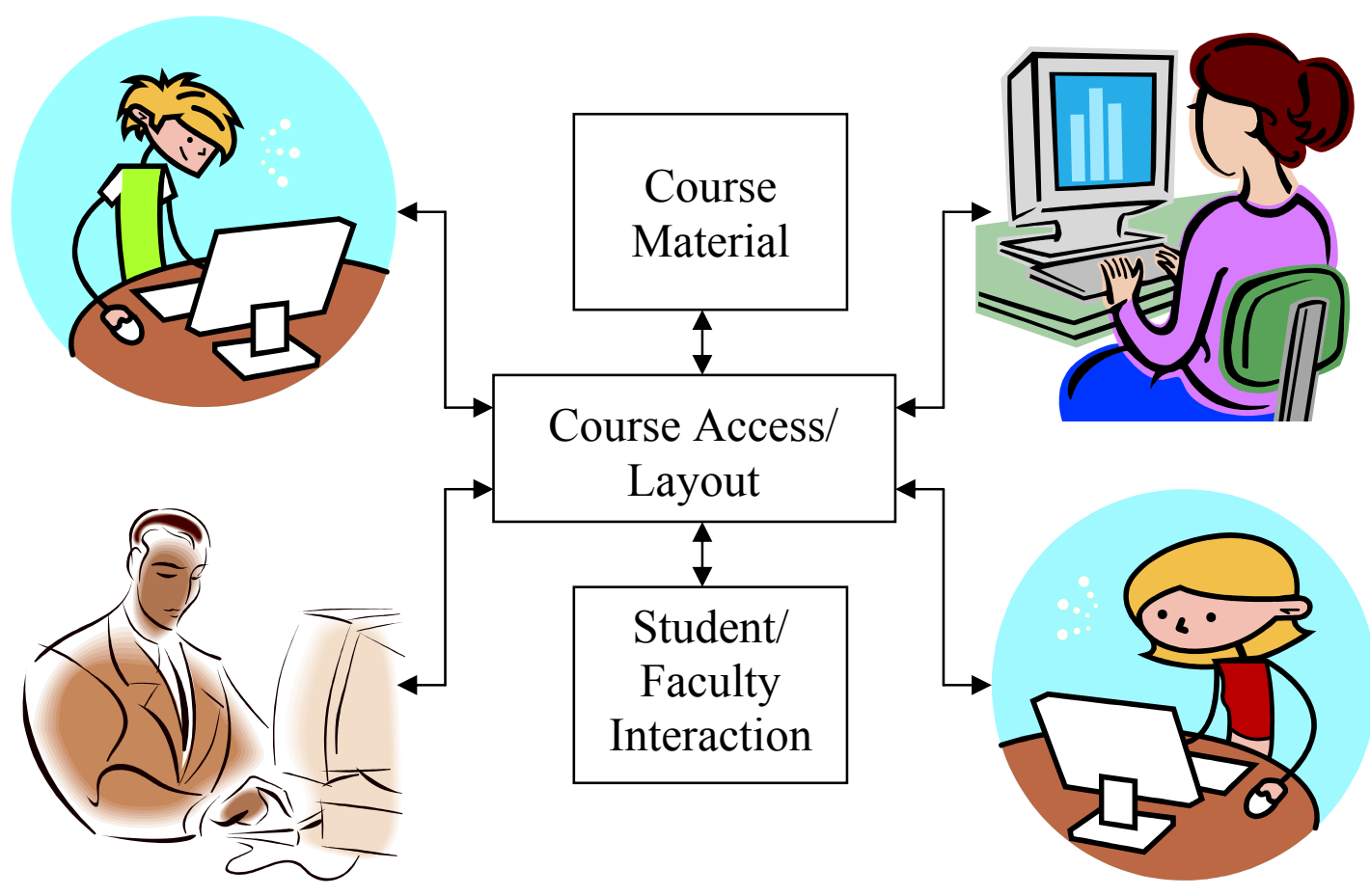

Figure 1. Online Classroom: Top Level Architecture

Each area of the online classroom can be categorized into one of the three top level components of the baseline architecture in a variety of ways. For the purpose of this analysis, the online classroom architecture is defined as follows:

1. Course Access/Layout (Learner-Interface Interaction)

a. Course Appearance

- Similar Look/Feel

- Ease of Use 
b. Course Structure

- Modular Format

- Sequence of Content

- Course Grade Distribution

2. Student/Faculty Interaction (Learner-Instructor, Learner-Learner Interactions)

a. Faculty Online Participation

- Weekly Discussions

- Frequently Asked Questions

- Course Objective Related Comments

- Real Life Examples: Sharing Knowledge/Experience

b. Online Peer-to-Peer Interaction

- Weekly Discussions

- Real Life Examples: Sharing Knowledge/Experience

c. Faculty Feedback to Students

- Team Feedback

- Individual Feedback

- General Class Feedback

d. Student Evaluation (post course completion)

- Course Evaluations

3. Course Material (Learner-Content Interactions)

a. Visual

- Course Syllabus and/or Getting Started

- Faculty Biography and Introduction

- Course Content

1. Presentation Slides

2. Lecture Notes

3. Assignment Descriptions

- Articles and other Supplemental Resources

- Reference Material

b. Verbal

- Audio Lectures

- Webconferences

c. External

- Textbooks

- CDs

For the twelve courses analyzed, each of these course components is implemented to various degrees by each of the course instructors. In some cases, a component may be used in a similar fashion by all instructors, in other cases an instructor may differ in the use of a component from one instantiation of a course to the next. We discuss the course data in more detail in the following sections. 


\section{Longitudinal View of Course Deliveries}

Each of the SEEM department's online instructors has the latitude to deliver course content to the students in a way that they view as most effective in meeting the three primary objectives we established for asynchronous online learning: to provide equivalent in-class learning, with comparable student feedback, and a manageable instructor course load. The result is a variety of preferred methods to apply the course components to course delivery. In addition, the same online course can be taught by more than one instructor. Thus, online course architectures not only vary from one course to another, but also vary from instructor to instructor within the same course, and can even vary with the same instructor in different instantiations of the same course.

Table 1 shows how the 37 courses that were analyzed for this paper were spread over the four semesters from Fall 2005 through to Fall 2006. Note that there were 15 different instructors, labeled by letters from $\mathrm{A}$ through $\mathrm{O}$, that taught various instantiations of the listed courses. When multiple or duplicate letters are listed, these represent multiple instantiations or sections of the same course, possibly taught by the same instructor, within any one semester.

Table 1. Online SEEM Department Courses from Fall 2005 to Fall 2006

\begin{tabular}{|c|c|c|c|c|c|}
\hline Course & Fall 2005 & Spring 2006 & Summer 2006 & Fall 2006 & Total \\
\hline EM600 & A & & A & A & 3 \\
\hline SYS601 & & B & & & 1 \\
\hline SYS611 & D & & D & C, D & 4 \\
\hline SYS612 & F & E, F & G & E, F & 6 \\
\hline SYS625 & J, J & I, J, J & I & H,J & 8 \\
\hline SYS640 & K & & & K & 2 \\
\hline SYS645 & L & & & & 1 \\
\hline SYS650 & N & M, N & M & N, N & 6 \\
\hline SYS655 & & K & & & 1 \\
\hline SYS660 & B & & B & B & 3 \\
\hline EM750 & & & O & & 1 \\
\hline EM680 & & & & G & 1 \\
\hline Total: & $\mathbf{9}$ & $\mathbf{9}$ & $\mathbf{7}$ & $\mathbf{1 2}$ & $\mathbf{3 7}$ \\
\hline
\end{tabular}

\section{Defining the Course Components}

The course components used for the analysis were developed using the earlier defined baseline architecture as a guideline. A few of the course components remain the same from course to course in our sample set. For example, all courses use the WebCT LMS and all courses provide presentation materials and supplemental course material in a modular format. These particular course components were not included in the analysis. The rest of the course components vary from a small degree to widely. For example, some courses used a varying number of weekly discussions from a few to a dozen. Some courses have exams, other courses have no exams. The areas of variation form the basis 
of our analysis for this paper and include the following 22 course components that were measured for each instantiation of each course:

Course Appearance:

\section{Similar Look/Feel}

Course Grading and Assignment Distribution:

2. $\%$ Online Discussion

3. \% Online Quizzes

4. \% Test/Exams

5. \% Individual Assignments

6. \% Team Assignments

7. Number of Online Quizzes

8. Number of Individual Assignments

9. Number of Team Assignments

10. Number of Textbooks

11. Student/Faculty and Student/Student Interaction:

12. Number of Weekly Discussions

13. Number of Student Weekly Posts Required

14. Total Number of Student Posts Required

15. Total Number of Faculty Discussion Posts

16. Type of Faculty Feedback Provided

17. Faculty Online Feedback Rating

Delivery of Course Material (Verbal):

18. Number of Audio Lectures

19. Number of Web Conferences

Student Evaluation Return Data

20. Number of Students in Course

21. Number of Students that Responded to the Evaluation

22. Overall Return Rate

In most cases, the measured values for each instantiation of each course were determined primarily by direct observation or review of the online course by the primary author. In a few cases, some of the values were self reported by the course instructor. Three components of the course - course appearance, and faculty feedback type and rating required additional definition in order to complete the measurement to obtain values that could be analyzed. These definitions are provided in the following subsections. 


\section{Course Appearance: Similar Look/Feel}

The following criteria were used to evaluate similar look/feel for each course:

Low (1): Looks nothing like the basic university online course template. The Course Menu is not used. The links provided look much different than most of the other online courses. May not even have a university logo shown on the Homepage or elsewhere.

Medium (3): Has a somewhat similar look and feel to most of the university online courses. Course Menu or Homepage has links to a Getting Started and/or syllabus, Course Content, Communication Tools including Chat Rooms, Mail and Discussion areas. An assignments link may be used as well as a Course Survey link. Student profiles may be used. A Scorecard or My Grades link is available.

High (5): Highest level of similarity of look and feel to most university online courses in the SEEM department. A typical Homepage has the classic university logo; icons and links include a Getting Started and/or syllabus, Course Content, Communication Tools, Assignments, and a Course Survey link. The Course Menu is used and provides links to most of the commonly used icons including above, Student profiles, Faculty profile, Chat Rooms, Mail Discussions, Scorecard or My Grades. Optionally, the course has links to the university library and the WebCT tutorial.

\section{Faculty Feedback Type}

The faculty feedback type was defined as follows:

Low (1): Grades are usually provided on completed assignments during the course. Specific feedback is not typically provided on graded assignments, although grades are provided, some feedback may be provided upon request. Typical feedback provided is of a more general nature and focuses on performance rather than course content.

Medium (3): Grades are provided during course on completed assignments. Some level of feedback is provided intermittently during the course or upon request for both graded assignments and general individual progress and team direction.

High (5): Grades are provided during course on completed assignments within a specified timeframe. Specific feedback is provided on all graded assignments and students receive weekly feedback either on team direction, individual progress, or a combination.

\section{Faculty Online Feedback Rating}

The Faculty Online Feedback Rating was calculated using the following weights for each time feedback was provided to the student:

1: Grade provided only. 
2: Detailed comments provided only, no grade provided.

2: A grade and a solution set provided.

3: Both a grade and detailed feedback (may include a solution set) provided.

To calculate the Faculty Online Feedback Rating, each time feedback was provided to the student for individual or team assignments, tests, online quizzes, or team progress reports, the appropriate weight was applied and each instance summed. Note that faculty participation postings were not included in this rating.

\section{Student Course Evaluation Return Rates}

Our online university started collecting automated course feedback from students in the Fall 2005 semester. From this data, the student's evaluations were collected for each instantiation of the online Systems Engineering and Engineering Management (SEEM) courses from the Fall 2005 through to the Fall 2006 semester. Return rates are shown from a longitudinal view for each semester in Table 2. For the thirty seven classes analyzed, 379 of the 483 students who took these SEEM online courses from Fall 2005 to Fall 2006 submitted a course evaluation, for an overall return rate of 78\%. This return rate is considered substantial compared to the normal student survey return rates which are typically much less than $50 \%$.

Table 2. Summary of Student Evaluation Return Rates

\begin{tabular}{|c|c|c|c|}
\hline Fall 2005 & Spring 2006 & Summer 2006 & Fall 2006 \\
\hline $75 \%$ & $100 \%$ & $55 \%$ & $30 \%$ \\
\hline $81 \%$ & $64 \%$ & $64 \%$ & $77 \%$ \\
\hline $100 \%$ & $81 \%$ & $72 \%$ & $86 \%$ \\
\hline $100 \%$ & $100 \%$ & $93 \%$ & $67 \%$ \\
\hline $33 \%$ & $100 \%$ & $73 \%$ & $82 \%$ \\
\hline $67 \%$ & $100 \%$ & $100 \%$ & $100 \%$ \\
\hline $100 \%$ & $100 \%$ & $33 \%$ & $75 \%$ \\
\hline $80 \%$ & $100 \%$ & & $82 \%$ \\
\hline $82 \%$ & $77 \%$ & & $100 \%$ \\
\hline & & & $74 \%$ \\
\hline & & & $72 \%$ \\
\hline & & & $24 \%$ \\
\hline $\mathbf{8 6 \%}$ & $\mathbf{8 8 \%}$ & $\mathbf{6 9 \%}$ & $\mathbf{7 1 \%}$ \\
\hline
\end{tabular}

\section{Student Course Evaluation Metrics}

The results from the student evaluations used for this analysis included student replies to two "Overall" Course and Instructor statements:

1. Course: "Overall the quality of the course was excellent."

2. Instructor: "Overall the instructor was an effective teacher."

And the student's rating, on a Likert scale of: 
- Strongly Agree (5)

- Agree (4)

- Neither Agree nor Disagree (3)

- Disagree (2)

- Strongly Disagree (1)

These resulted in 10 course evaluation metrics. From this data, each response was assigned the value shown in parentheses and the number of responses in each category were weighted and summed, to calculate the Average Score (mean), a standard deviation for the average score, and a Median and Mode for each of the two questions, for each instantiation of the course. This added another 8 evaluation metrics Then the percentage of each Likert response for both the course and instructor were also included in the correlation analysis for a subtotal of 28 evaluation metrics.

Next, a Net Supporter \% for each question was calculated using an adaptation of Frederick F. Reichheld's net promoter methodology. (Frederick, 2003) The Net Supporter \% was calculated by taking the percentage of promoters (Strongly Agree) and subtracting the percentage of detractors (Neither Agree nor Disagree, Disagree and Strongly Disagree) based on the answer to the "Overall" Course and Instructor statements, adding another 2 metrics and getting us up to 30 metrics.

And the final data included was a Yes or No response from each student as to whether or not they would recommend our university's online system to others. The recommendation rate was also calculated and included in the analysis. Overall, 33 evaluation metrics for each course instantiation - taken either directly from the evaluation or calculated from the evaluation results - were included in the analysis. These are summarized below.

Summarized Evaluation Metrics:

"Overall the quality of the course was excellent."

$1-5 \quad$ Likert Scale Responses

6-10 \% of each Likert Scale Response

$11-15$ Mean, Std Deviation of Mean, Mode, Median, \% Net Supporters

"Overall the instructor was an effective teacher."

16-20 Likert Scale Responses

$21-25 \%$ of each Likert Scale Response

26-30 Mean, Std Deviation of Mean, Mode, Median, \% Net Supporters

Recommend Webcampus

$31 \quad$ \# Yes

$32 \quad$ \# No

33 Recommendation \%

Next, the analysis was performed. 


\section{Method: Mapping Course Components to Course Deliveries}

For the analysis, we mapped the defined course components to the student evaluation metrics for the 37 instantiations of the 12 SEEM courses. First a matrix was compiled consisting of the 22 course components and the 33 student evaluation metrics, for each course section. Next, a one-to-one correlation coefficient, $r$, was calculated between each of the 22 course components and each of the 33 student evaluation metrics, again for each of the 37 course instantiations. Results were analyzed for potential areas showing a high correlation so that further statistical analyses could be performed.

Linear regression analyses were performed in some of the more promising areas. These were followed by multiple linear regressions, combining the data from various course components as independent variables to see the relationship to specific dependent variables selected from the student satisfaction metrics. The conclusion from the process was that more data was required to obtain statistically significant and repeatable results. However, there appeared to be some areas that were worth investigating further when more data became available. These are the areas discussed in more detail in the Findings section.

\section{Findings}

A total of 22 course components of the online classroom were compared to 33 student evaluation metrics to find relationships between the course components of the online classroom and student's perception of their learning experience in that online classroom. While these perceptions may be individually biased, as a whole, the majority of our online university student body is comprised of full-time working professionals whose main interest is applying what they have learned to their job. Thus, the student's learning experience is viewed as essential in continuing their education and their perception of individual learning is of value to the university in improving the overall online learning experience.

While there are individual findings related to each set of data - the online class delivery methods chosen by each instructor and the course evaluation results - the findings in this study focus on the relationships between the two sets of data. Pertinent observations related to the course components of the online classroom are also included. However, the primary goal is to apply the findings to determine the value of each course component of the online classroom based on the students' perceptions.

The findings can be viewed in two ways. First, there is the type and degree of effect each component of the online classroom has on the student's overall perception of the course and the instructor. In most areas this effect is statistically uncertain due to the small sample size and the large variation in the data; however, the direction of the effect (positive or negative) and in some cases, a significant correlation, can be noted. Second, each area of student perception can be evaluated to determine those aspects of the online classroom that appeared to have the most effect on that perception. Findings are presented from both viewpoints -- the viewpoint of the course components and the 
viewpoint of the student evaluation results. The findings are sorted starting with the highest correlation and/or most statistically significant, in the following sections.

\section{Student/Faculty and Student/Student Interaction}

The most significant relationship between course components and student satisfaction was found in the areas of online discussion and faculty feedback. These areas supported the learner-instructor and learner-learner interaction types. (Moore, 1989) The number of weekly posts required from students $(\mathrm{r}=0.59)$ when a discussion was underway, and the total number of posts required throughout the course $(\mathrm{r}=0.55)$ correlated positively to the number of students who agreed with the statement: "Overall the quality of the course was excellent." Thus, students who participated at a high level in the online course (primarily due to the requirement to participate to earn a higher grade) were more satisfied with the online course, in general.

The average number of faculty posts that were part of the course discussions (excluding answers to questions, posting of material, feedback on assignments) positively correlated $(\mathrm{r}=0.53)$ to the number of students who strongly agreed to the statement: "Overall the instructor was an effective teacher." Therefore, the majority of students were highly satisfied with those instructors that participated often in the ongoing weekly discussions. The type of feedback the instructor provided to the students also positively correlated $(\mathrm{r}=0.50)$ to the number of students who strongly agreed to that same statement. In this case, students were more highly satisfied with the instructor when the type of feedback they received was detailed, and the feedback was received more often throughout the course.

\section{Student Evaluation Return Data}

When a multiple linear regression analysis was performed on the student evaluation return rate and the type of faculty feedback and faculty online feedback rating, the relationship proved to be statistically significant $(\mathrm{p}<0.01)$. The percentage of student returns positively correlated to the type of faculty feedback $(\mathrm{r}=0.59)$ and the faculty online feedback rating $(\mathrm{r}=0.59)$, implying that the higher the quality of feedback provided from the instructor to the student, the more likely the student was to provide feedback to the instructor when requested.

\section{Course Appearance: Similar Look/Feel}

The largest effect the level of similar look/feel of each online course appeared to have on the student evaluations was on the level of student agreement $(\mathrm{r}=0.42)$ with the statement: "Overall the quality of the course was excellent." This corroborates the findings from Swan, et al. (2000, p. 516) where consistency and student satisfaction was found to significantly correlate $(\mathrm{r}=0.333, \mathrm{p}<.05)$. However, similar look/feel was also negatively correlated $(\mathrm{r}=-0.36)$ to the percentage of students who strongly agreed with this statement, implying that additional work on the interface between the students and the 
university's online course look/feel should be investigated to increase the level of satisfaction, overall.

Similar look/feel also positively correlated to several other course components: \% of grade for online discussions $(\mathrm{r}=0.52)$, total number of weekly discussion posts required $(\mathrm{r}=0.70)$, and the requirement for a student profile $(\mathrm{r}=0.61)$. Thus, most of the university courses leverage online discussion and student profiles in their classrooms, components used for building online communities.

Similar look/feel negatively correlated to: $\%$ of grade for test/exams $(r=-0.71)$ and the use of audio lectures $(\mathrm{r}=-0.59)$ and automated online quizzes $(\mathrm{r}=-0.61)$ implying that these online course components are not [yet] typically used in the most common classroom layouts. However, as discussed in a later section, the use of audio lectures $(\mathrm{r}=0.37)$ and automated online quizzes $(\mathrm{r}=0.38)$ were found to most positively correlate to the percentage of students who strongly agreed with this statement: "Overall the quality of the course was excellent." Thus, the lack of standard use of these course components represents a current gap in the university's online classrooms.

\section{Course Grading and Assignment Distribution}

The most notable positive impact of grading distribution $\%$ on course evaluation results is in the area of online discussions. The online discussions positively correlated to both the number of students who recommended the online university to others $(r=0.45)$ and also to the number of students who agreed with the statement: "Overall the quality of the course was excellent." ( $\mathrm{r}=0.50)$. Similarly, the use of online quizzes had a notable positive correlation $(\mathrm{r}=0.38)$ to the percentage of students who strongly agreed to that same statement.

\section{Delivery of Course Material (Verbal)}

Similar to online quizzes, the use of audio lectures positively correlated $(\mathrm{r}=0.37)$ to the percentage of students who strongly agreed to the statement: "Overall the quality of the course was excellent." The use of a web conferencing system during the online course did not appear to have a significant correlation to student satisfaction in any area of the evaluation. While the continued use of the web conferencing system is encouraged, the use of web conferencing should not replace other valuable aspects of the online classroom architecture.

\section{"Overall the instructor was an effective teacher."}

From the viewpoint of the student evaluations, $44 \%$ of the students strongly agreed and $37 \%$ agreed with the statement: "Overall the instructor was an effective teacher", for a total of $81 \%$ agreement with the statement. Again, the focus is on improvement in the level of students that strongly agree with the statement. The two course components most positively related to the percentage of students who strongly agreed with this statement were the average number of faculty posts that were part of the course 
discussions (excluding answers to questions, posting of material, feedback on assignments) $(\mathrm{r}=0.53)$ and the type of feedback the instructor provided to the students $(\mathrm{r}=0.50)$.

\section{"Overall the quality of the course was excellent."}

From the viewpoint of the student evaluations, nearly half of the students (47\%) agreed with the statement: "Overall the quality of the course was excellent." and another $28 \%$ strongly agreed with the statement, for a total of $75 \%$. However, in order to achieve evaluation comparable student feedback ratings in our online courses as we do in our in class deliveries, the majority of the students should strongly agree with this statement. The percentage of students who strongly agreed with this statement was most positively correlated with the use of audio lectures $(r=0.37)$ and automated online quizzes $(r=0.38)$ in the online classroom. It should be noted that the use of the quizzes in our online courses is as a material review or refresher. Quizzes can be repeatedly taken, and questions are rotated for each quiz session, until the student has mastered that portion of the course material.

\section{Future Research}

As an extension of this effort, future research can include:

1. An expansion of the above analysis to include all six course related areas and all eight instructor related areas of the student evaluation, shown in Tables 3 and 4. The current analysis only addressed the final question shown in each table.

Table 3. Student Evaluation: Course Related Statements

\section{Course Evaluation}

1. The course had continuity, not skipping unrelatedly from place to place and was easy to navigate and locate information.

2. My work is graded promptly.

3. The textbook was useful.

4. Exam and quiz questions were a good test of my understanding of the subject.

5. The material was adequately covered in the allotted time.

6. Overall the quality of the course was excellent.

\section{Table 4. Student Evaluation: Instructor Related Statements}

\section{Instructor Evaluation}

1. Clearly explains the objectives and the grading system at the start of the course.

2. Is prepared for class.

3. Presents material in an organized manner.

4. Has command of the subject.

5. Successfully communicates the subject matter.

6. Is available to students on matters related to the course.

7. Is fair and consistent.

8. Overall the instructor was an effective teacher. 
2. Longitudinal studies which focus on the most popular online courses. The study results would be based on changes that have been made to the online classroom components over time for that specific course and how that compares to the students' perceptions of each instantiation of that course.

3. A broader sample set of the university's courses and student evaluations that include courses from other engineering disciplines, the business school and arts and sciences.

4. Further study that addresses the confounding factors involved in this analysis. The students' experience and satisfaction level are not completely determined by the online course components included in the analysis. For example, across the 37 instantiations of the courses, class sizes varied from 3 to 21 students. Instructor personalities and styles can also have a profound effect on student satisfaction with both the instructor and the course. These confounding factors deserve more attention in future research.

5. A comparison between the online courses and ground courses in these same two areas of overall course evaluation and overall instructor evaluation using a more generic set of classroom components that address both the online and face to face classroom.

\section{Conclusions}

From this analysis the most valued components of the online classroom from the perspective of the student appear to be (based on a small sample of courses):

1. A high level of faculty participation in the online course content discussions (over and above answering questions, posting material and providing feedback).

2. High quality detailed faculty feedback provided on a weekly basis on assignments, individual and team progress, etc...

3. Automated online quizzes to be used repetitively as needed to master the course material.

4. Audio lectures to subsidize lecture notes. Note that in the most popular course (most instantiations) the audio lectures are also supplemented with text scripts.

Inclusion of these architectural components in the online classroom should be prioritized above other components in the development and enhancement of online courses. We also found that the higher the quality of feedback provided from the instructor to the student, the more likely the student was to provide feedback to the instructor when requested. Note that the components valued most highly in the online classroom do not conceptually differ from those valued in a traditional classroom. 


\section{Bibliography}

- Frederick F. Reichheld (2003). The One Number You Need to Grow. Harvard Business Review, December 12.

- $\quad$ Fredericksen, E., Pickett, A., Shea, P., Pelz, W., Swan, K. (2000). Student Satisfaction and Perceived Learning with Online Courses: Principles and Examples from the SUNY Learning Network. Journal of Asynchronous Learning Networks, Volume 4, Issue 2 - September 2000.

- Garrison, D. R., Anderson, T., Archer, W. (2001). Critical thinking, cognitive presence, and computer conferencing in distance education. American Journal of Distance Education, 15(1), 7-23.

- Hillman, D. C., Willis, D. J., \& Gunawardena, C. N. (1994). Learner-interface interaction in distance education: An extension of contemporary models and strategies for practitioners. The American Journal of Distance Education, 8(2), 30-42.

- Moore, M. (1989). Editorial: Three types of interaction, The American Journal of Distance Education, 3 (2), 1-6.

- Parker, A. (1999). Interaction in Distance Education: The Critical Conversation. AACE Journal, 1 (12), pp. 13-17. Charlottesville, VA: AACE.

- Pennotti, M., Smith, C., and Verma, D. (2004). A Systems Engineering Approach to the Design of Asynchronous Online Systems Engineering Courses. In Proceedings from the International Systems Engineering Conference (ICSE) and the International Council of Systems Engineering (INCOSE) 2004 Region II Conference, Las Vegas, Nevada, September 15-18, 2004.

- Sener, J, Humbert, J. (2002) Student Satisfaction with Online Learning: An Expanding Universe. Elements of Quality Online Education: Practice and Direction, Volume 4 in the Sloan-C series.

- Swan, K., Shea, P., Fredericksen, E., Pickett, A. \& Maher, G. (2000). Course Design Factors Influencing the Success of Online Learning. In Proceedings of 2000 (pp. 513-518). Chesapeake, VA: AACE. 